\title{
Early and Persistent Hemothorax and Pneumothorax
}

\author{
Brandon R. Bruns ${ }^{1}$ - Jose J. Diaz ${ }^{1}$
}

Published online: 19 September 2015

(C) Springer International Publishing AG 2015

\begin{abstract}
The incidence of traumatic injury to the thorax is estimated at up to $40 \%$ of patients that require hospitalization. The vast majority of these injuries can be managed with observation. However, the presence of pneumothorax or hemothorax has traditionally mandated tube thoracostomy placement and the inherent morbidities that may arise. Persistent pneumothorax is typically defined as the presence of pneumothorax and/or air leak for 5-7 days after tube placement. This morbidity may be managed expectantly or with video-assisted thoracoscopic surgery (VATS). The most feared complication after hemothorax is the presence of retained blood and the risk of infection that follows. Most authorities support the early use of VATS to resolve retained hemothoraces with the hopes of avoiding more invasive procedures aimed at the treatment of fibrothorax and empyema.
\end{abstract}

Keywords Hemothorax · Pneumothorax · Traumatic .

Persistent $\cdot$ Traumatic hemothorax $\cdot$ Traumatic pneumothorax

\section{Introduction}

Thoracic trauma is a primary cause of morbidity and mortality in the multiply injured patient and accounts for approximately $25 \%$ of trauma-related deaths annually $[1,2]$. Pneumothorax

This article is part of the Topical Collection on Blunt Trauma to the Chest

Brandon R. Bruns

bbruns@umm.edu

Jose J. Diaz

jdiaz@umm.edu

1 Program in Trauma, R Adams Cowley Shock Trauma Center at the University of Maryland School of Medicine, 22 S Greene St., S4D07, Baltimore, MD 21201, USA and hemothorax are common findings in patients with thoracic injury and therefore demand mention.

\section{Pneumothorax}

\section{Identification and Diagnosis}

\section{History and Physical Examination}

Initial evaluation of the traumatically injured patient consists of a systematic evaluation of the patient utilizing the principles of Advanced Trauma Life Support (ATLS). Tachypnea and respiratory distress are potential findings that may alert the astute clinician to the presence of a pneumothorax or other pulmonary pathology. Examination of the lungs can reveal decreased breath sounds or tympany on percussion. Although, these findings lack the sensitivity to be solely relied upon and can be difficult to observe in a bustling trauma center. The diagnosis of tension pneumothorax remains a clinical, not a radiographic diagnosis. A late diagnostic finding is tracheal deviation away from the side of injury. Additionally, a hyperexpanded and asymmetric chest wall may be detected. Hemodynamic instability secondary to decreased venous return to the heart is a late and potentially lethal sign of tension pneumothorax.

Initial imaging has traditionally consisted of supine chest radiography in the traumatically injured patient. Pneumothorax is diagnosed when pleural markings are not visualized projecting to the chest wall, but instead, gas has escaped from the lung parenchyma and created a space between the lung and the pleura. Additional findings suggestive of pneumothorax on chest radiography include the "deep sulcus sign" and the presence of subcutaneous gas within the tissues of the chest wall or 
neck. If an excessive amount of gas escaped into the subcutaneous tissues, crepitus may be palpated.

The rationale behind routine chest radiography in blunt trauma has recently been questioned. A study performed at a level I trauma center illustrated that of 484 blunt trauma patients evaluated, $16(3.3 \%)$ had significant intra-thoracic injuries. In assessing the providers pretest probability for injury, they found that a low suspicion for injury was associated with an extremely low rate of significant intra-thoracic trauma [3]. With that said, it is still our practice to perform initial chest radiograph on the vast majority of traumatically injured patients.

In an effort to identify blunt trauma patients most likely to benefit from chest radiograph, the NEXUS Chest Study has identified seven clinical criteria predictive of major chest trauma: age greater than 60 years, rapid deceleration mechanism, chest pain, intoxication, altered mental status, distracting injury, and tenderness to the chest wall on palpation [4]. Investigators report a sensitivity of $99.7 \%$ and a negative predictive value of $99.9 \%$ when evaluating blunt trauma patients older than 14 years [5] (Table 1).

Recent studies have shown ultrasonography to be a noninvasive and non-radiation requiring study that can accurately diagnose pneumothorax in the bluntly injured trauma patient $[6,7]$. Ultrasound has consistently been shown to have better sensitivity and specificity than chest radiography in the detection of pneumothorax, with chest radiography having varying sensitivity from 28 to $75 \%$, but with specificity of $100 \%$ [ , 9]. The apposition of the parietal and visceral pleura creates a "sliding" that is not present when air infiltrates this space (Fig. 1). Ultrasound has many features making it an attractive initial imaging option including its portability, repeatability, and the ability to obtain real-time and dynamic images by a member of the treatment team.

Computed tomography (CT) imaging of the chest has become commonplace in the current era and is invaluable in the diagnosis of blunt aortic injury and other life-threatening

Table 1 NEXUS chest proposed criteria for safely reducing thoracic imaging in blunt trauma patients over 14 years of age. In the absence of the above signs, the incidence of significant chest injury is exceedingly low $[4,5]$

\begin{tabular}{l} 
Nexus chest \\
\hline Blunt trauma patients greater than 14 years of age \\
Age greater than 60 years \\
Mechanism of injury-RAPID deceleration \\
Pain in chest \\
Presence of intoxicants \\
Altered mental status or level of consciousness \\
Distracting injury \\
Tenderness to palpation of the chest wall
\end{tabular}

conditions [10-12]. However, the practice of obtaining chest $\mathrm{CT}$ after normal chest radiograph is controversial. In patients with a normal chest $\mathrm{x}$-ray who then underwent chest $\mathrm{CT}$, a 2013 study showed $82 \%$ of patients proceeded to have a normal CT, $13.2 \%$ had clinically minor injuries, $2.7 \%$ clinically insignificant injuries, and only $2 \%$ of patients had clinically major injuries on CT after normal chest $\mathrm{x}$-ray [13].

Some pneumothoraces are not visible on initial chest $\mathrm{x}$-ray, instead initially being visualized on computed tomography (CT) of the chest; these are labeled as occult pneumothoraces. Utilization of ultrasound as an adjunct to chest $\mathrm{x}$-ray has been illustrated to accurately diagnose occult pneumothorax with an accuracy that approaches that of CT $[14,15]$. These occult findings are of uncertain clinical significance, but concerns for tension pneumothorax with the application of positive pressure ventilation, such as is required during operative therapy, have been voiced. Some have suggested oblique chest x-ray as an adjunctive measure to identify occult pneumothorax in the unstable patient [16].

\section{Initial Treatment}

Classic teaching has mandated placement of tube thoracostomy once the diagnosis of pneumothorax has been made. Recent evidence has illustrated that the placement of 14-Fr pigtail catheter is sufficient to evacuate traumatic pneumothorax [17]. In a subsequent randomized control trial, 40 patients were randomized to either a 28 -Fr chest tube or a 14 Fr pigtail catheter for traumatic pneumothorax, with the 14-Fr pigtail catheter group having less pain and similar success rates compared to those receiving larger chest tubes [18•].

Suggested initial treatment of presumptive tension pneumothorax has been the placement of a 16-gauge angiocatheter in the second intercostal space at the mid-clavicular line [19]. However, recent evidence suggests that the second intercostal space may be inadequate in a significant number of patients. At the University of Southern California, Inaba and colleagues utilized a fresh cadaveric model and were able to show the standard 5-mm angiocatheter suggested for needle decompression was of inadequate length to reach the pleural space in $57.5 \%$ of cadavers' second intercostal space. However, when placed in the fifth intercostal space, they would adequately decompress $100 \%$ of the cadavers studied [20]. In contradistinction, an investigation in blunt trauma patients undergoing CT imaging of the chest showed that commonly employed angiocatheters are of insufficient length to reach the pleural space laterally, and many are too short to reach in the second intercostal space [21].

Treatment of occult pneumothorax is often debated, as CT imaging has the ability to detect small pneumothoraces of unknown clinical significance. Single institution studies have suggested that observation of occult pneumothoraces is safe 
Fig. 1 The left panel shows the characteristic "sliding" image present when the parietal and visceral pleura are well opposed, whereas the right panel shows a characteristic still image when air infiltrates the space (pneumothorax)

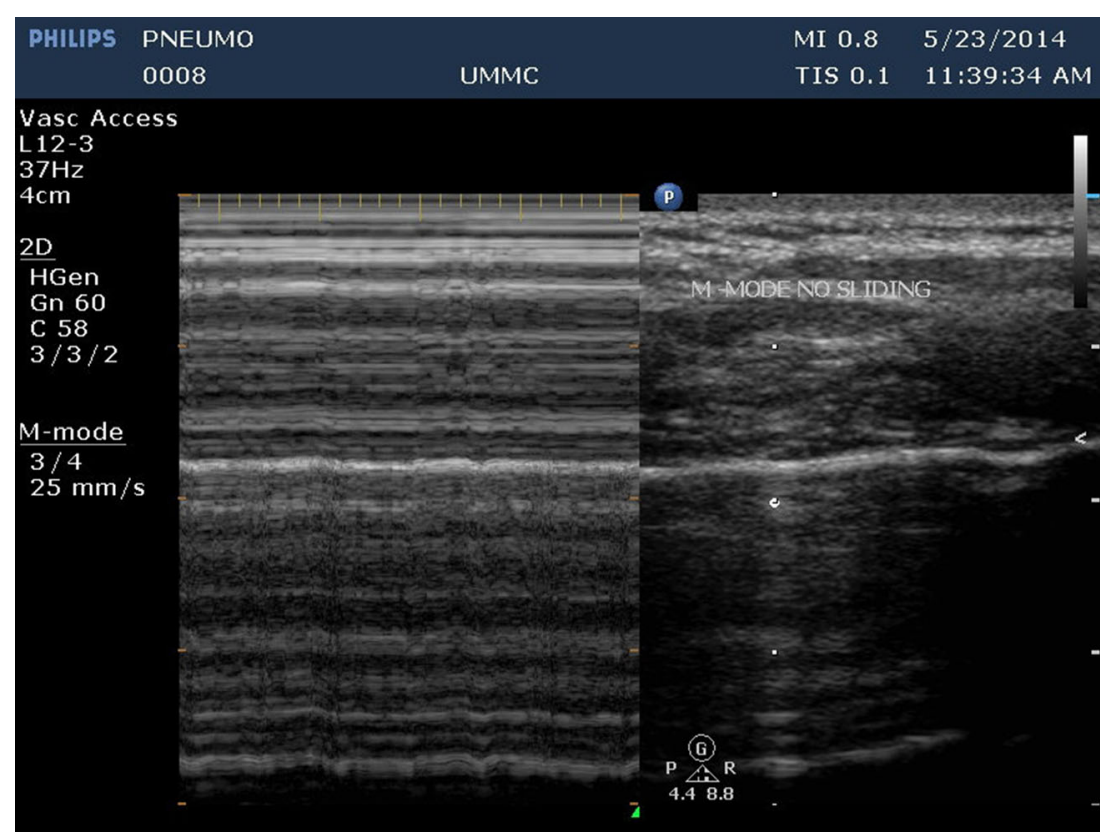

and does not lead to tension pneumothorax with the application of positive pressure ventilation. Additionally, the authors show that patients managed without chest tube placement have shorter hospital lengths of stay [22]. A 2011 American Association for the Surgery of Trauma (AAST)-sponsored multi-institutional prospective study showed similar findings, concluding that the majority of bluntly injured patients with occult pneumothoraces can be safely observed. The authors found that worsening respiratory distress and progression of pneumothorax were associated with failure of observation, with no influence provided by the application of positive pressure ventilation [23•].

\section{Treatment for Persistent Pneumothorax}

The definition of persistent pneumothorax varies throughout the literature, but we typically view a pneumothorax as persistent if an air leak is present for greater than 5-7 days after placement of thoracostomy tube. In the vast majority of traumatically injured patients with persistent pneumothorax and air leak secondary to pulmonary parenchymal injury, the air leak will resolve without treatment as the lung heals. However, studies have shown decreased length of hospitalization and fewer chest tube days with early video-assisted thoracoscopic surgery (VATS) therapy and application of a topical sealant, pleurodesis, or pulmonary parenchymal resection or repair [24-26].

Alternatively, a technique which we occasionally utilize is the placement of a Heimlich valve at the distal aspect of the thoracostomy tube. The Heimlich valve acts as a one-way valve for gas and fluid, thus the patient can safely be managed without the cumbersome underwater drainage system [27].
We tend to employ this technique in patient's likely to have a hostile thoracic cavity or who carry a high operative risk of morbidity, for example those with emphysematous lung disease.

\section{Complications and Outcomes}

Overall, when compared to a penetrating mechanism of injury, patients with a blunt mechanism of injury tend to have longer intensive care unit stays, more ventilator days, and more tube thoracostomy days [28]. Some suggest that the utilization of a clinical practice algorithm, especially in patients with an elevated chest Abbreviated Injury Score (AIS), can decrease the morbidity associated with tube thoracostomy management and eventual removal [29, 30]. Though our current practice is to obtain a chest radiograph on removal of thoracostomy tubes, others have proposed the utility of such a film is low in the absence of clinical signs exhibited by the patient [31].

\section{Hemothorax}

\section{Identification and Diagnosis}

Similar diagnostic principles exist for both hemothorax and pneumothorax. Physical examination may reveal decreased breath sounds or dullness to percussion on the affected side, though this finding is exceedingly variable and difficult to detect in a noisy trauma environment. Chest radiography is most commonly utilized for definitive diagnosis and will illustrate blunting of the costophrenic angle with varying amounts of opacification within the hemithorax. However, 
ultrasound is also a widely accepted diagnostic adjunct and has been shown to be more sensitive than, and at least as specific, as plain film radiography [32, 33]. In consideration of which diagnostic technique to utilize, the clinician must consider the physiologic state of the patient and always remember, in the hemodynamically abnormal patient, the ideal maneuver is likely the placement of bilateral chest tubes to both diagnose and treat pneumothorax and hemothorax.

\section{Initial Treatment}

Traditionally, traumatic hemothorax has been managed with the placement of a large-bore tube thoracostomy into the affected hemithorax. A small prospective study of 227 patients has suggested that placement of a 14-Fr pigtail catheter for traumatic hemothorax is adequate to evacuate blood with equivalent tube durations, insertion complications, and rate of failure [17]. In the majority of cases, we utilize tube thoracostomy for hemothorax drainage, though we have had success with image-guided placement of pigtail catheters into hemorrhagic collections. This option is especially appealing in the elderly population and those patients with anatomically inaccessible collections.

A 2012 American Association for the Surgery of Trauma (AAST) multicenter trial highlights the importance of early evacuation of retained hemothorax. Investigators found a $26.8 \%$ incidence of empyema among patients with a posttraumatic retained hemothorax. They identified rib fractures, Injury Severity Score (ISS) greater than 25, and additional procedures to evacuate retained hemothorax as independent predictors of empyema formation [34•]. This underscores the importance of obtaining adequate drainage with the fewest number of thoracic manipulations possible.

\section{Treatment for Persistent Hemothorax}

The management of persistent hemothorax has garnered much attention over the past 5-10 years, with a focus on early evacuation via video-assisted thoracoscopic surgery (VATS). Many investigators have shown and advocate for early thoracoscopic exploration in an effort to evacuate any retained blood products and prevent formation of fibrothorax and empyema [35-38]. Early evacuation and decreased incidence of empyema formation should lead to a decreased need thoracotomy, a more invasive and painful procedure.

In a 2011 AAST multi-institutional prospective trial, DuBose and colleagues enrolled 328 patients with retained hemothorax at 20 individual trauma centers. VATS was performed in $33.5 \%$ of those patients with $22.2 \%$ of patients requiring thoracotomy. The authors stress that $25 \%$ of the patients required at least two procedures to adequately clear their hemothorax [39]. Investigators have also shown that implementation of a clinical pathway for management of retained hemothorax leads to VATS in more patients, in addition to decreasing hospital cost and improving outcomes [40].

\section{Complications and Outcomes}

Retained hemothorax is reported to occur in approximately $20 \%$ of patients with thoracic trauma and hemothoax [41]. Because of the concern for bacterial contamination and subsequent empyema formation, great emphasis is placed on early evacuation of any retained clot. Our institutional guideline is to perform a chest radiograph on the day following tube thoracostomy placement. If opacity obscures the costophrenic angle, a chest $\mathrm{CT}$ scan is performed, as studies have illustrated that plain film radiography is insufficient to predict the need for thoracoscopic intervention [42]. Retained blood estimated at greater than $500 \mathrm{~mL}$ or opacification of $1 / 3$ of the hemithorax are indications to proceed with VATS.

Additionally, pneumonia exists as a very real concern after thoracic trauma and hemothorax formation. Issues surrounding pre-procedural administration of antibiotics to prevent pneumonia, and possibly empyema, are still undergoing debate. In 2012, the Eastern Association for the Surgery of Trauma published a practice management guideline stating
Fig. 2 Proposed algorithm for the management of suspected intra-thoracic trauma in both blunt and penetrating mechanisms of injury $[4,5]$

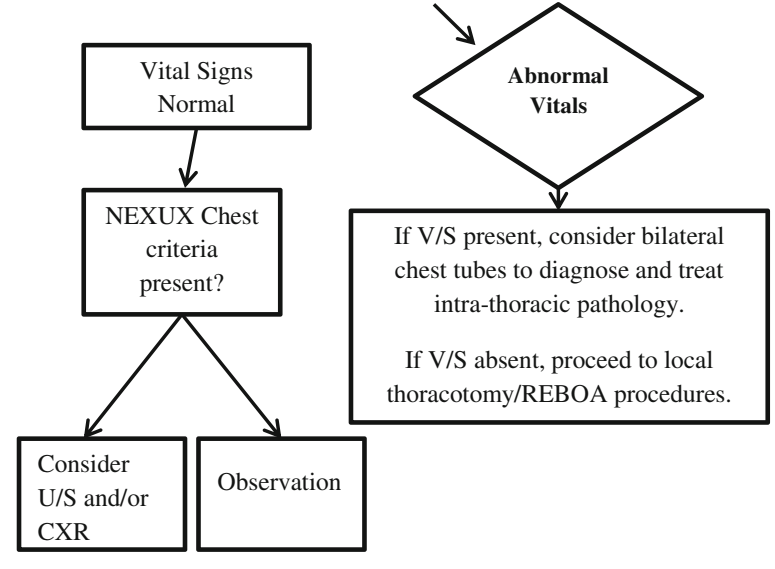


"there is insufficient published evidence to support any recommendation either for or against this practice" [43]. However, in 2013, Bradley and colleagues utilized the AAST PostTraumatic Retained Hemothorax database and found that lack of pre-procedure antibiotics was an independent risk factor pneumonia formation [44]. Current institutional protocol at our institution leaves the administration of antibiotics at the discretion of the practitioner.

\section{Conclusions}

The management of hemothorax and pneumothorax continues to evolve towards a more minimally invasive and thoughtful approach, while at the same time obviating the physiologic instability that often accompanies both conditions. However, the clinician must not forget or lose the ability to perform urgent and facile invasive maneuvers in the hemodynamically unstable patient (Fig. 2).

\section{Compliance with Ethics Guidelines}

Conflict of Interest Brandon R. Bruns and Jose J. Diaz declare no conflicts of interest.

Human and Animal Rights and Informed Consent This article does not contain any studies with human or animal subjects performed by any of the authors.

\section{References}

Papers of particular interest, published recently, have been highlighted as:

- Of importance

1. Kaewlai R, Avery LL, Asrani AV, Novelline RA. Multidetector CT of blunt thoracic trauma. Radiographics. 2008;28(6):1555-70.

2. Gasparri M, Karmy-Jones R, Kralovich KA, Patton Jr JH, Arbabi S. Pulmonary tractotomy versus lung resection: viable options in penetrating lung injury. J Trauma. 2001;51(6):1092-5. discussion 1096-7.

3. Calderon G, Perez D, Fortman J, Kea B, Rodriguez RM. Provider perceptions concerning use of chest $\mathrm{x}$-ray studies in adult blunt trauma assessments. J Emerg Med. 2012;43(4):568-74.

4. Rodriguez RM, Hendey GW, Mower W, Kea B, Fortman J, Merchant G, et al. Derivation of a decision instrument for selective chest radiography in blunt trauma. J Trauma. 2011;71(3):549-53.

5. Rodriguez RM, Anglin D, Langdorf MI, Baumann BM, Hendey GW, Bradley RN, et al. NEXUS chest: validation of a decision instrument for selective chest imaging in blunt trauma. JAMA Surg. 2013;148(10):940-6.

6. Donmez H, Tokmak TT, Yildirim A, Buyukoglan H, Ozturk M, Yasar Ayaz U, et al. Should bedside sonography be used first to diagnose pneumothorax secondary to blunt trauma? J Clin Ultrasound. 2012;40(3):142-6.

7. Nandipati KC, Allamaneni S, Kakarla R, Wong A, Richards N, Satterfield J, et al. Extended focused assessment with sonography for trauma (EFAST) in the diagnosis of pneumothorax: experience at a community based level I trauma center. Injury. 2011;42(5):511-4.

8. Blaivas M, Lyon M, Duggal S. A prospective comparison of supine chest radiography and bedside ultrasound for the diagnosis of traumatic pneumothorax. Acad Emerg Med. 2005;12(9):844-9.

9. Wilkerson RG, Stone MB. Sensitivity of bedside ultrasound and supine anteroposterior chest radiographs for the identification of pneumothorax after blunt trauma. Acad Emerg Med. 2010;17(1):11-7.

10. Patterson BO, Holt PJ, Cleanthis M, Tai N, Carrell T, Loosemore TM, et al. Imaging vascular trauma. Br J Surg. 2012;99(4):494-505.

11. Chen MY, Miller PR, McLaughlin CA, Kortesis BG, Kavanagh PV, Dyer RB. The trend of using computed tomography in the detection of acute thoracic aortic and branch vessel injury after blunt thoracic trauma: single-center experience over 13 years. J Trauma. 2004;56(4):783-5.

12. Bruckner BA, DiBardino DJ, Cumbie TC, Trinh C, Blackmon SH, Fisher RG, et al. Critical evaluation of chest computed tomography scans for blunt descending thoracic aortic injury. Ann Thorac Surg. 2006;81(4):1339-46.

13. Kea B, Gamarallage R, Vairamuthu H, Fortman J, Lunney K, Hendey GW, et al. What is the clinical significance of chest CT when the chest $\mathrm{x}$-ray result is normal in patients with blunt trauma? Am J Emerg Med. 2013;31(8):1268-73.

14. Soldati G, Testa A, Sher S, Pignataro G, La Sala M, Silveri NG. Occult traumatic pneumothorax: diagnostic accuracy of lung ultrasonography in the emergency department. Chest. 2008;133(1):204-11.

15. Soldati G, Testa A, Pignataro G, Portale G, Biasucci DG, Leone A, et al. The ultrasonographic deep sulcus sign in traumatic pneumothorax. Ultrasound Med Biol. 2006;32(8):1157-63.

16. Matsumoto S, Kishikawa M, Hayakawa K, Narumi A, Matsunami K, Kitano M. A method to detect occult pneumothorax with chest radiography. Ann Emerg Med. 2011;57(4):378-81.

17. Kulvatunyou N, Joseph B, Friese RS, Green D, Gries L, O'Keeffe $\mathrm{T}$, et al. 14 french pigtail catheters placed by surgeons to drain blood on trauma patients: is 14-fr too small? J Trauma Acute Care Surg. 2012;73(6):1423-7.

18. Kulvatunyou N, Erickson L, Vijayasekaran A, Gries L, Joseph B, Friese RF, et al. Randomized clinical trial of pigtail catheter versus chest tube in injured patients with uncomplicated traumatic pneumothorax. Br J Surg. 2014;101(2):17-22. Authors have shown, in a randomized fashion, that 14-French pigtail catheters are as safe and effective as traditional chest tube placement in uncomplicated traumatic pneumothorax.

19. American College of Surgeons - Committee on Trauma. Advanced trauma life support program student course manual. 9th ed. Chicago: American College of Surgeons; 2012.

20. Inaba K, Branco BC, Eckstein M, Shatz DV, Martin MJ, Green DJ, et al. Optimal positioning for emergent needle thoracostomy: a cadaver-based study. J Trauma. 2011;71(5):1099-103. discussion 1103.

21. Sanchez LD, Straszewski S, Saghir A, Khan A, Horn E, Fischer C, et al. Anterior versus lateral needle decompression of tension pneumothorax: comparison by computed tomography chest wall measurement. Acad Emerg Med. 2011;18(10):1022-6.

22. Wilson H, Ellsmere J, Tallon J, Kirkpatrick A. Occult pneumothorax in the blunt trauma patient: tube thoracostomy or observation? Injury. 2009;40(9):928-31.

23. Moore FO, Goslar PW, Coimbra R, Velmahos G, Brown CV, Coopwood TB, Jr, et al. Blunt traumatic occult pneumothorax: Is observation safe?-results of a prospective, AAST multicenter study. J Trauma. 2011;70(5):1019,23; discussion 1023-5. Authors showed that observation of occult pneumothorax is 
safe in the absence of clinical deterioration or progression of pneumothorax, even in the face of positive pressure ventilation.

24. Fabbrucci P, Nocentini L, Secci S, Manzoli D, Bruscino A, Fedi M, et al. Video-assisted thoracoscopy in the early diagnosis and management of post-traumatic pneumothorax and hemothorax. Surg Endosc. 2008;22(5):1227-31.

25. Schermer CR, Matteson BD, Demarest III GB, Albrecht RM, Davis VH. A prospective evaluation of video-assisted thoracic surgery for persistent air leak due to trauma. Am J Surg. 1999;177(6):480-4.

26. Carrillo EH, Kozloff M, Saridakis A, Bragg S, Levy J. Thoracoscopic application of a topical sealant for the management of persistent posttraumatic pneumothorax. J Trauma. 2006;60(1):111-4.

27. Heimlich HJ. Heimlich valve for chest drainage. Med Instrum. 1983;17(1):29-31.

28. Helling TS, Gyles III NR, Eisenstein CL, Soracco CA. Complications following blunt and penetrating injuries in 216 victims of chest trauma requiring tube thoracostomy. J Trauma. 1989;29(10):1367-70.

29. Martin M, Schall CT, Anderson C, Kopari N, Davis AT, Stevens P, et al. Results of a clinical practice algorithm for the management of thoracostomy tubes placed for traumatic mechanism. Springerplus. 2013;2:642, 1801-2-642. eCollection 2013.

30. Menger R, Telford G, Kim P, Bergey MR, Foreman J, Sarani B, et al. Complications following thoracic trauma managed with tube thoracostomy. Injury. 2012;43(1):46-50.

31. Pacanowski JP, Waack ML, Daley BJ, Hunter KS, Clinton R, Diamond DL, et al. Is routine roentgenography needed after closed tube thoracostomy removal? J Trauma. 2000;48(4):684-8.

32. Mowery NT, Gunter OL, Collier BR, Diaz Jr JJ, Haut E, Hildreth A, et al. Practice management guidelines for management of hemothorax and occult pneumothorax. J Trauma. 2011;70(2):510-8.

33. McEwan K, Thompson P. Ultrasound to detect haemothorax after chest injury. Emerg Med J. 2007;24(8):581-2.

34. DuBose J, Inaba K, Okoye O, Demetriades D, Scalea T, O'Connor $\mathrm{J}$, et al. Development of posttraumatic empyema in patients with retained hemothorax: results of a prospective, observational AAST study. J Trauma Acute Care Surg. 2012;73(3):752-7. Authors have shown that there is a significant incidence of empyema in patient with retained hemothorax $(\mathbf{2 6 . 8 \%})$ and independent predictors of empyema formation included rib fractures, ISS $>$ 25 , and multiple thoracic interventions aimed at resolving the retained hemothorax.

35. Meyer DM, Jessen ME, Wait MA, Estrera AS. Early evacuation of traumatic retained hemothoraces using thoracoscopy: a prospective, randomized trial. Ann Thorac Surg. 1997;64(5):1396-400. discussion 1400-1.

36. Carrillo EH, Richardson JD. Thoracoscopy in the management of hemothorax and retained blood after trauma. Curr Opin Pulm Med. 1998;4(4):243-6.

37. Velmahos GC, Demetriades D. Early thoracoscopy for the evacuation of undrained haemothorax. Eur J Surg. 1999;165(10):924-9.

38. Smith JW, Franklin GA, Harbrecht BG, Richardson JD. Early VATS for blunt chest trauma: a management technique underutilized by acute care surgeons. J Trauma. 2011;71(1):1025. discussion 105-7.

39. DuBose J, Inaba K, Demetriades D, Scalea TM, O'Connor J, Menaker J, et al. Management of post-traumatic retained hemothorax: a prospective, observational, multicenter AAST study. J Trauma Acute Care Surg. 2012;72(1):11-22. discussion 22-4; quiz 316.

40. Morrison CA, Lee TC, Wall Jr MJ, Carrick MM. Use of a trauma service clinical pathway to improve patient outcomes for retained traumatic hemothorax. World J Surg. 2009;33(9):1851-6.

41. Stewart RM, Corneille MG. Common complications following thoracic trauma: their prevention and treatment. Semin Thorac Cardiovasc Surg. 2008;20(1):69-71.

42. Velmahos GC, Demetriades D, Chan L, Tatevossian R, Cornwell III EE, Yassa N, et al. Predicting the need for thoracoscopic evacuation of residual traumatic hemothorax: chest radiograph is insufficient. J Trauma. 1999;46(1):65-70.

43. Moore FO, Duane TM, Hu CK, Fox AD, McQuay Jr N, Lieber ML, et al. Presumptive antibiotic use in tube thoracostomy for traumatic hemopneumothorax: an eastern association for the surgery of trauma practice management guideline. J Trauma Acute Care Surg. 2012;73(5 Suppl 4):S341-4.

44. Bradley M, Okoye O, DuBose J, Inaba K, Demetriades D, Scalea T, et al. Risk factors for post-traumatic pneumonia in patients with retained haemothorax: results of a prospective, observational AAST study. Injury. 2013;44(9):1159-64. 